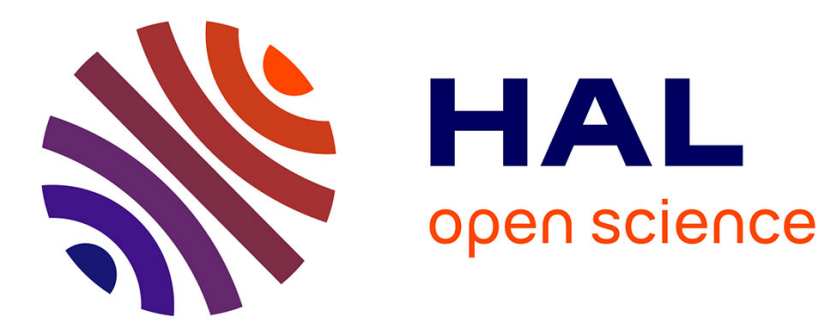

\title{
Services Personalization Approach for a Collaborative Care Ecosystem
}

\author{
Thais Andrea Baldissera, Luis M. Camarinha-Matos
}

\section{To cite this version:}

Thais Andrea Baldissera, Luis M. Camarinha-Matos. Services Personalization Approach for a Collaborative Care Ecosystem. 17th Working Conference on Virtual Enterprises (PRO-VE), Oct 2016, Porto, Portugal. pp.443-456, 10.1007/978-3-319-45390-3_38. hal-01614591

\section{HAL Id: hal-01614591 \\ https://hal.inria.fr/hal-01614591}

Submitted on 11 Oct 2017

HAL is a multi-disciplinary open access archive for the deposit and dissemination of scientific research documents, whether they are published or not. The documents may come from teaching and research institutions in France or abroad, or from public or private research centers.
L'archive ouverte pluridisciplinaire HAL, est destinée au dépôt et à la diffusion de documents scientifiques de niveau recherche, publiés ou non, émanant des établissements d'enseignement et de recherche français ou étrangers, des laboratoires publics ou privés. 


\title{
Services Personalization Approach for a Collaborative Care Ecosystem
}

\author{
Thais Andrea Baldissera, Luis M. Camarinha-Matos \\ Faculty of Science and Technology and Uninova-CTS, Universidade NOVA de Lisboa \\ Campus de Caparica, Portugal \\ \{tab@uninova.pt,$\underline{\text { cam@uninova.pt }\}}$
}

\begin{abstract}
Ageing entails several limitations, calling for assistance services adapted to particular elderly's needs and life style. Provision of such may involve many stakeholders, including relatives, caregivers, professional care people, suppliers and other support entities. The use of collaborative networks has been proposed as a mean of integrating contributions from distinct service providers and promoting collaboration to seek the best options among multiple services. Despite of advances in collaborative networks for elderly care, current research and development in care services are chiefly focused on the development of isolated services, considering only a single service provider, emphasizing excessively techno-centric solutions. The need for dealing with personalization of care services in a collaborative environment is rising in importance and, thus, requires a flexible way to guide the process of ranking and selecting services. In this paper, a method based on fuzzy logic to identify services and corresponding providers thought service adherence criteria is presented. To show the feasibility of the method, an illustrative scenario of elderly life style in which services are ranked based on multiple views, from single to composite services, to show how distinct integrations may result in different recommendations.
\end{abstract}

Keywords: Collaborative Business Services, ICT and Ageing, Collaborative Networks, Personalization, and Fuzzy Logic.

\section{Introduction}

In recent years, one of the most important changes in the history of humanity has been taking place: the increasing demographic shift related to elderly population. Current trends suggest that the global elderly population above 80 years old will increase by $217 \%$ in 2050 when compared to 2015 . Also, the elderly population is supposed to surpass young people in many regions of the world, according to the Help Age International Organization [1], which accentuates the importance of research on aging-related matters in our society [2-4].

As people age, additional needs are required to maintain individuals healthy, and within good quality of life. In this process, classifying an individual as elderly goes beyond the use of age as a determinant factor. Indeed, individual aging aspects, such as the living context, personal capabilities and competences also contribute to better characterize an elderly individual. Each elderly individual may require very specific 
services (e.g., care and assistance) in accordance to this/her life context. As a consequence, a particular service may be perfectly adequate for an individual and completely useless for another one. Therefore, a relevant issue refers to the need of integrated and personalized services.

The notion of personalized service means that the service is tailored to each individual [5-9]. For several authors [5; 6; 10], personalizing a service involves an agreement between customers and providers (and all other involved stakeholders) through which they share information to be organized in an intelligent and adaptive way. This collaborative agreement allows reaching best experiences by those involved in providing personalized services, relevant and attractive to each customer, respecting the characteristics and the context of life of each one.

In this sense, care services should then be integrated, since they usually have influence on each other. The notion of collaborative business ecosystem for elderly care can assist on the integration of different services from distinct providers [11]. In addition, finding the best combination of services and service providers that cover customer's desires and life context, and following a collaborative network strategy is a though process. Many criteria for service composition can influence decisions, and frequent contextual analysis for service personalization and evolution. To facilitate the process of finding best composite service in the context of CBE, we propose: (i) an approach to model the main CBE stakeholder's requirements, and (ii) a mechanism to personalize services based on fuzzy cognitive maps.

The remainder of this paper is organized as follows: the introduction the research backgrounds in Section 2. Section 3 presents the CBE stakeholder's requirements that supports the approach. A fuzzy cognitive maps in the context of collaborative network environment to rank care services is presented in Sections 4. A practical application of the approach is shown in Section 5. Finally, the conclusion in Section 6 with a discussion on the main future work and conclusions.

\section{Research Background}

The main research question addressed in this work is: How to provide personalized and evolutionary collaborative care services for elderly in an effective and reliable way? And the pursued hypothesis is: Effective and reliable personalized and evolutionary services for elderly care can be provided if a suitable set of multiprovider business services are composed and integrated in the context of a collaborative network environment and supported by context awareness methods, mechanisms and systems.

The research is organized according to the following phases: (1) Collaborative Business Ecosystem Model and Personalization Mechanism Development; (2) Personalization Mechanism Refinement; (3) Personalization Mechanism Consolidation; (4) Evolution Mechanism Development; and (5) Collaborative Business Ecosystem Model and Evolution Mechanisms Consolidation.

This work follows the initial ideas presented in [11], where the proposed a Collaborative Business Ecosystem (CBE) was proposed for elderly care. The main goal of CBE is delivery of personalized and evolutionary care services. In the elderly care domain, personalization involves the analysis of the senior's life context for 
personalized service composition. For each change in the customer's context it is necessary to analyze the situation (in collaboration will all relevant stakeholders), and evolve the service to fit that context.

The simplified view of a support system for the CBE is presented in Fig. 1. In such ecosystem, the main intervenient actors are divided into two groups: (a) Elderly Living Environment (ELE), representing the elderly costumers and their ambient and context, including informal caregivers, such as family and friends, and all applications and devices with which they interact such as context aware devices; (b) Service Providers Environment (SPE), representing the care provision stakeholders, which has the goal of providing care and assistance services, facilitating support and companionship, all based on community participation with established trust.

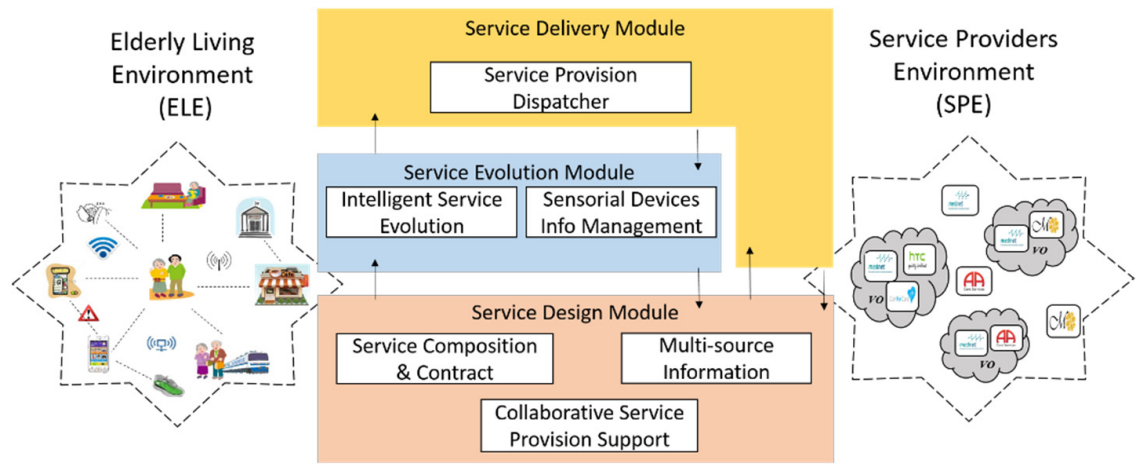

Fig. 1. Simplified view of the CBE System

To operate the CBE, three main modules are considered: (1) Service design module: responsible for receiving service requests from seniors and family and searching the providers and best services available for the senior and his/her living environment (ELE customer); (2) Service evolution module: responsible for analyzing context information and proposing a personalized and evolutionary care and assistance service for ELE customer; and (3) Service runtime module: responsible for notifying the SPE and delivering to ELE the care and assistance services according to the corresponding agreed terms.

This paper focuses on the first research phase (Collaborative Business Ecosystem Model and Personalization Mechanism Development) and proposes a mechanism based on fuzzy cognitive maps to identify the required services and corresponding providers.

\section{Elderly Care Ecosystem Stakeholders}

A Collaborative Business Ecosystem (CBE) may involve many elements, covering customers (elderly) and their preferences and needs, care and assistance services, and service provision organizations [11]. The organization of this ecosystem is according 
to four main areas: customer, care needs, service, and service providers. Customer is related to relevant information about elderly as a customer within the CBE. Care needs represent the major groups of necessities of individuals within the elderly community. A service represents a care service available within the ecosystem. Services are provided by service providers. In more detail:

- Customer: an accurate customer's profile is fundamental to identify the best option of care services. In CBE, a customer is characterized by personal attributes, constraints and life style. Personal attributes include gender, age, personality, family members, address, etc. Constraints refer to customer's physical and cognitive restrictions, and current and historical diseases. Life style captures customer's preferences, such as wishes, religion, social activities, technology usage, etc.

- Care Need: when requiring some care services, it is important to identify what are the customer's wishes and needs as well as their relative importance. A care need is directly connected to customer's profile, constraints and life style. In CBE, each care need belongs to an Area. Referring to the four life settings defined by the BRAID Bridging Research in Ageing and ICT Development - roadmap project [12]: independent living, health and care, occupation in life, and recreation in life as areas. Customers express care needs through a fuzzy scale to indicate their priority regarding each need, i.e., ranging from no to very high priority as shown in Fig. 2. A care need may have an impact (negative or positive) on other care needs. Identifying such impacts is necessary to provide adequate level of services according to multiple care needs of a particular customer.

- Service: to cover a care need, one or more care and assistance services might be available in the collaborative ecosystem. A fuzzy scale is associated to these services to indicate their level of coverage of a care need (from no coverage to very high coverage as shown in Fig. 2). CBE considers that service descriptions are kept in a Service Catalogue, to be consulted whenever is needed.

Care needs and services are linked to a taxonomy to classify what is required from the customer and what is provided by service providers. The taxonomy is important during the matching process, where CBE module seeks for services to attend a set of care needs. Both services and care needs can be linked to distinct levels in the taxonomy, which may enlarge or restrict the searching process. For example, consider the following snippet of a taxonomy for health and care (Fig. 3). A service can be linked to Remote monitoring, which means it attends care needs related to Follow-up monitoring and Regular monitoring. However, a care need linked to Physical compensation does not match a service that is assigned to Neurocognitive compensation in the taxonomy.

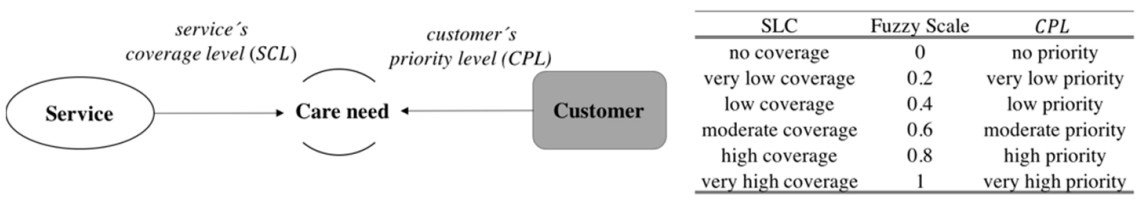

Fig. 2 Fuzzy scale level for service, care need and customer 
- Service Providers: have the goal of providing care and assistance services, facilitating support and companionship. Service providers include support and regulation entities, private companies, and/or governmental institutions. CBE can include several service providers, each one delivering its own services. It is supported by a virtual space or collaboration platform in which members (service providers) agree to create composite services as soon as good opportunities arise. This platform shall also facilitate the fast, dynamic, (desirably) on-the-fly partnership formation [13; 14]. As members of the ecosystem, partners remain prepared to engage in a composite service. When a market opportunity for a new personalized service appears, they engage in fast partnership creation (leading to a Virtual Organization - VO). The partnership remains while the package is still being delivered [15].

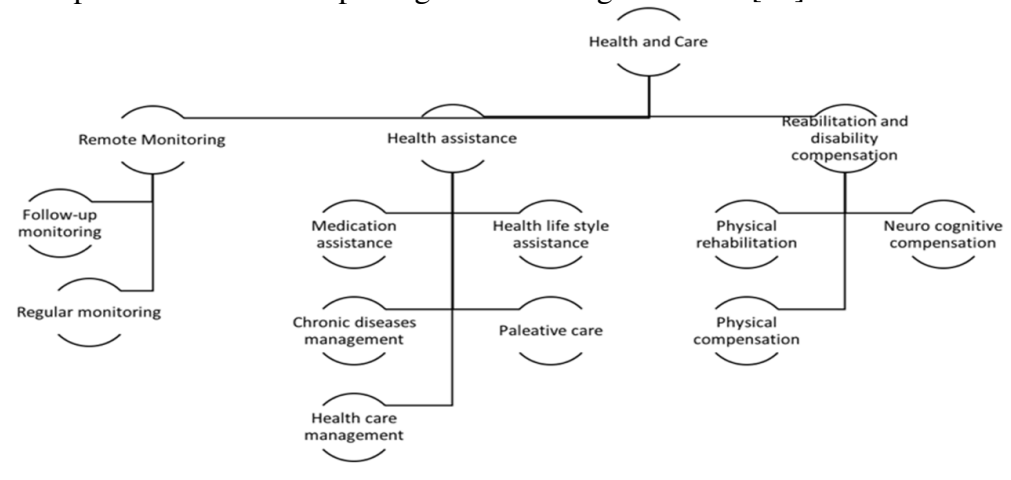

Fig. 3. Partial example of health and care taxonomy

Fig. 4 illustrates the stakeholders and their relationships within the CBE.

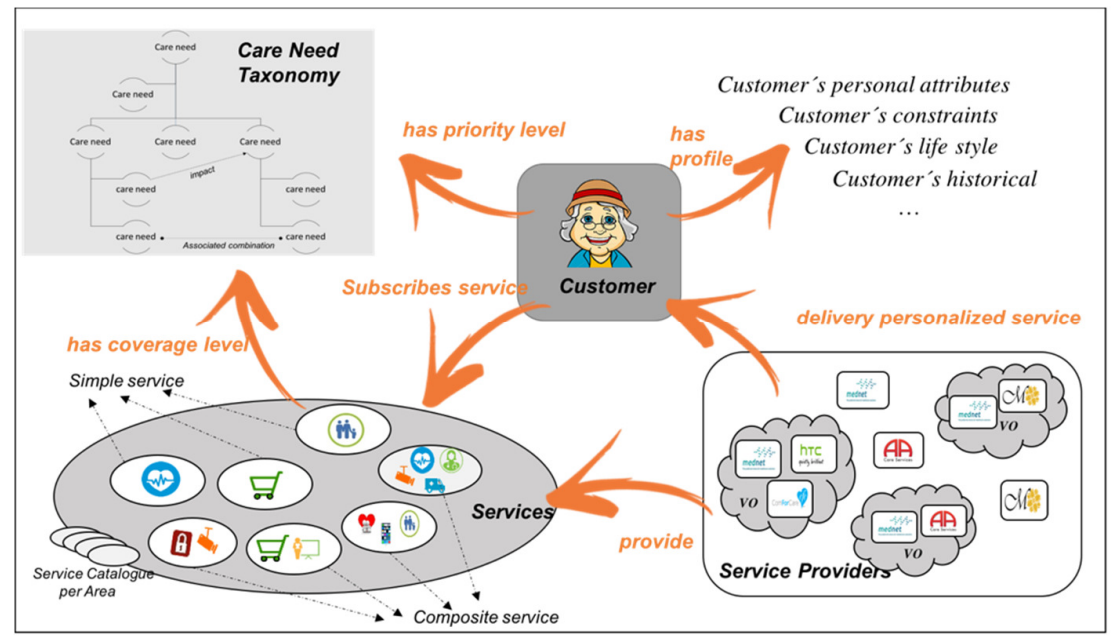

Fig. 4. CBE stakeholders and their relationships 


\section{A Fuzzy Cognitive Map for Elderly Care Service}

Based on the relevant concepts of the elderly care ecosystem described in previous section, a causal network was designed to support the computation of a ranking of care services. The proposed causal network is inspired on the Fuzzy Cognitive Map (FCM) Kosko [16]. However, it was enriched with utility and decision nodes to support the decision process. When selecting services within the CBE, distinct factors can influence positively or negatively this decision. Additionally, decisions are often not based on precise criteria. Thus, the use of a FCM is an appealing choice to support the approach. FCMs are fuzzy directed graphs with feedback, covering many nodes and directed edges that connect and represent the causal relations between those nodes, so nodes in FCM represent concepts while edges are causal connections. A positive edge from node A to node B means A causally increases B. Intuitively, a negative edge from $\mathrm{B}$ to $\mathrm{C}$ means that node $\mathrm{B}$ causally decreases $\mathrm{C}$. Causality is expressed in terms of a fuzzy degree, such as very low, low, moderate, high, very high, etc.

\section{Building the Fuzzy Map Network}

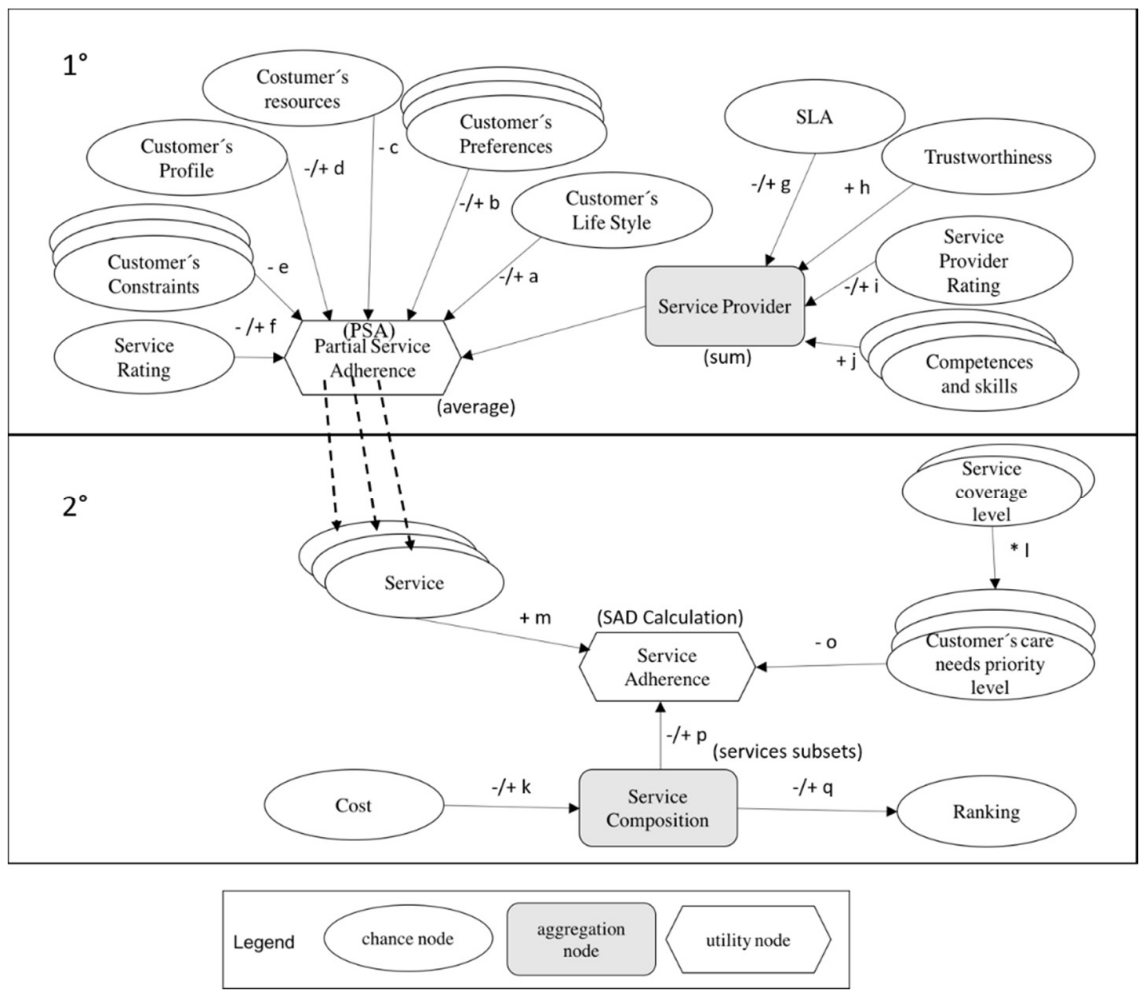

Fig. 5 The abstract model of the fuzzy causal network 
The proposed fuzzy causal network (FCN) has three types of nodes [17]: chance nodes representing uncertain domain entities, significant for causal reasoning (denoted by ovals), aggregation nodes indicating partial computation (denoted by rectangles), and utility nodes, corresponding to the fitness value of the map configuration (denoted by a hexagon). Fig. 5 presents the abstract model of fuzzy causal network, which is built in two layers. The first layer computes a partial service adherence without deeming the care needs (for each care service). The second layer takes into account the services ranked in the first layer and the customer care needs to compose multiple service options. The outcome of this layer is a ranking with service composition options that best fit the service provision.

Table 1 briefly describes the nodes of FCN. Except for utility node (Partial Service Adherence and Service Adherence), and aggregation node (Service Provider and Service Composition), all the others are represented by fuzzy variables in the range [0, 1]. This allows to initialize and analyze nodes whose values are imprecise.

Table 1. Nodes in the causal network

\begin{tabular}{|c|c|c|}
\hline Node & Semantics & Type \\
\hline Service Rating & The rating given by the ecosystem for a service & Chance \\
\hline Customer's constraints & The constraints expressed by the customer & Chance \\
\hline Customer's profile & The properties representing a customer profile & Chance \\
\hline Customer's resources & The resource set possessed by a customer & Chance \\
\hline Customer's preferences & The preference set expressed by the customer & Chance \\
\hline Customer's life style & The properties that characterize the customer life style & Chance \\
\hline SLA given by the provider & $\begin{array}{l}\text { A value ( } 0 \text { to } 10) \text { representing the level of agreement a } \\
\text { provider states about a service }\end{array}$ & Chance \\
\hline $\begin{array}{l}\text { Organization } \\
\text { trustworthiness }\end{array}$ & $\begin{array}{l}\text { The trustworthiness level given by the ecosystem to an } \\
\text { organization }\end{array}$ & Chance \\
\hline Service provider rating & The rating given by the ecosystem to a service provider & Chance \\
\hline Competences and skills & $\begin{array}{l}\text { The list of competences of a provider for a particular } \\
\text { service }\end{array}$ & Chance \\
\hline Service Provider & A aggregator for provider characteristics & Aggregation \\
\hline Partial Service Adherence & $\begin{array}{l}\text { The adherence of a service without considering the } \\
\text { customer care needs }\end{array}$ & Utility \\
\hline Cost & A total cost of a composite care service & Chance \\
\hline Partial Service Adherence & $\begin{array}{l}\text { A value of partial adherence that was calculated in the first } \\
\text { layer }\end{array}$ & Chance \\
\hline Service coverage level & The SCL given by the service to a care need & Chance \\
\hline Customer's care needs & The care needs set of a particular customer & Chance \\
\hline Service Adherence & The adherence of a service with care needs & Utility \\
\hline Service Composition & The composition of services & Aggregation \\
\hline Ranking & Ranked list of services & Chance \\
\hline
\end{tabular}

* Chance nodes. They are qualified using fuzzy variables ranging from 0 to 1 . These nodes and their respective degrees are determined by rules established by the services. For example, consider a service $s_{1}$ inserted in the service catalog represented by a 
node in the FCN. This service provides a particular resource that requires from the customer good knowledge on advanced smartphone features. The node representing this service will positively influence the service adherence whether the customer owns advanced knowledge on smartphones. On the other hand, if the customer is not familiar with this technology, the node will be considered negative.

For valued nodes, such as service rating and trustworthiness, a degree scale according to the value intervals is considered. For example, service rating may correspond to values between 0 to 10 , separated in two intervals $[0,5] \mathrm{e}[5.1,10]$. The first interval represents negative influence and the second interval is the positive influence. The degrees are also established in subintervals. Fig. 6 illustrates the service rating influence scale. For example, if the rating value is 8.6 , the influence is positive and the corresponding fuzzy scale is +0.8 .

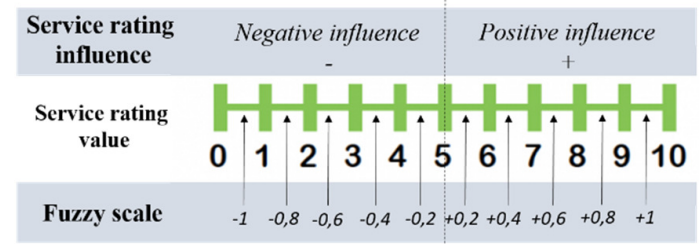

Fig. 6 Example of service rating influence scale example

When there is more than one node for an information, the influence degree is computed by the average among the nodes. For example, a customer constrained by health complications and memory disability will have the final constraint computed by the average between them.

* Aggregation node. Service Provider is an aggregation node because multiple providers can provide the same service. This aggregation sums the received influences. The same concept is applied to Service Composition. Thus different kinds of composition are built to create the service ranking.

* Utility node. For each service, the partial service adherence (PSA) is calculated. The value of PSA is the starting point for the second phase, where the partial service adherence will become a chance node. It receives a service partial adherence value. Service has a positive influence on Service Adherence node.

Service adherence (SAD) combines partial service adherence (PSD) and service coverage level (SCL) of the customer's care needs. SAD is calculated by multiplying these values.

SAD considers a service and all customer's care needs. However, service composition can bring even better solutions to attend the elderly and it should be taken into account. As such, for each service composition, the service composition node represents the maximum coverage of the composite services for each customer's care needs. 


\section{Service Personalization Process}

The proposed service personalization process is divided into four phases (Fig. 7):

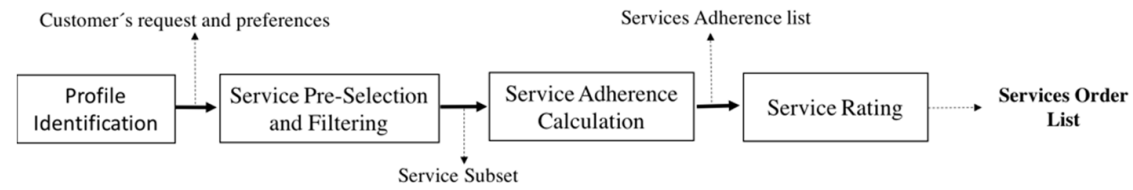

Fig. 7. Personalization Mechanism Steps

Profile Identification. Initially the customer's profile identification and customer's requests are collected, representing a preliminary step.

Service Pre-Selection and Filtering. In sequence, services that cover customer's wants are selected in phase 2 . Selected services are filtered through restrictions. For instance, the customer's geographical area will constrain the searching to available services in a particular region. Customer's constraints determine the best ranked (and also the not eligible) care services for attending the senior. Life style information and personality [18] can suggest customer's preference for service choice and service evolution.

Service Adherence calculation. Service adherence represents a compatibility index between the service, customer's profile and customer's care needs. The larger the service adherence is, the more personalized the service is for the customer's profile. Adherence represents a potential decision criteria to rank care services. A composite business service is a collection of related and (to some extent) integrated business services that provide a specific business solution. Service composition can bring even better solutions to attend elderly and it should be taken into account.

Service Rating. The main considered parameter is service adherence that covers customer's requests, human constraints, preferences, etc. However, financial constraints and management strategies must also be considered for rating. For instance, service's cost and number of services providers.

\section{Case Study}

In this phase, the purpose is to evaluate the feasibility of the model. As a preliminary validation, we applied some illustrative scenarios-examples to give us confidence to move on to more complex cases. Thus, enlarging studied scenarios with non-trivial cases and new validation strategies will reinforce the applicability of our approach.

To guide the fuzzy map network application, let consider the following Mary's scenario. Fig. 8 shows the first stage, profile identification and care needs request. 


Costumer's identification
MARY'S PROFILE is female, widow, 69 years old, lives in Sunnyvale

Fig. 8 Mary's identification

After customer's profile acquisition, the next step is service subset selection. Let's imagine that five potential services to attend Mary's care needs are found. Among these services, the filtering process verifies that two of them are not available for Mary. The first one because it is not delivered in her geographical location and the second one because it is not suitable for diabetics. So, the available services for Mary's request are three services called s1, s2, and s5.

The causal network is then started. Considering service s1 like a regular health monitoring service, Fig. 9 illustrates a first part of the causal network for the example. Note that s1 requirements (defined in the first step) are compared with Mary's profile and requests. For instance, when s1 was included in the service catalogue, a recommendation was that s1 is not advised for seniors above 80 years old. As Mary is 69 , her profile causally increases partial service adherence. In relation to resources, s1 requires mobile internet to make better use (although it is not mandatory). As Mary does not have mobile internet, this situation causally decreases partial service adherence. About Mary's constraints, memory disability and health complications have negative influence on the partial service adherence. The influence of these constraints is calculated as the average of the influences of the various constraints (two constraints in this example).

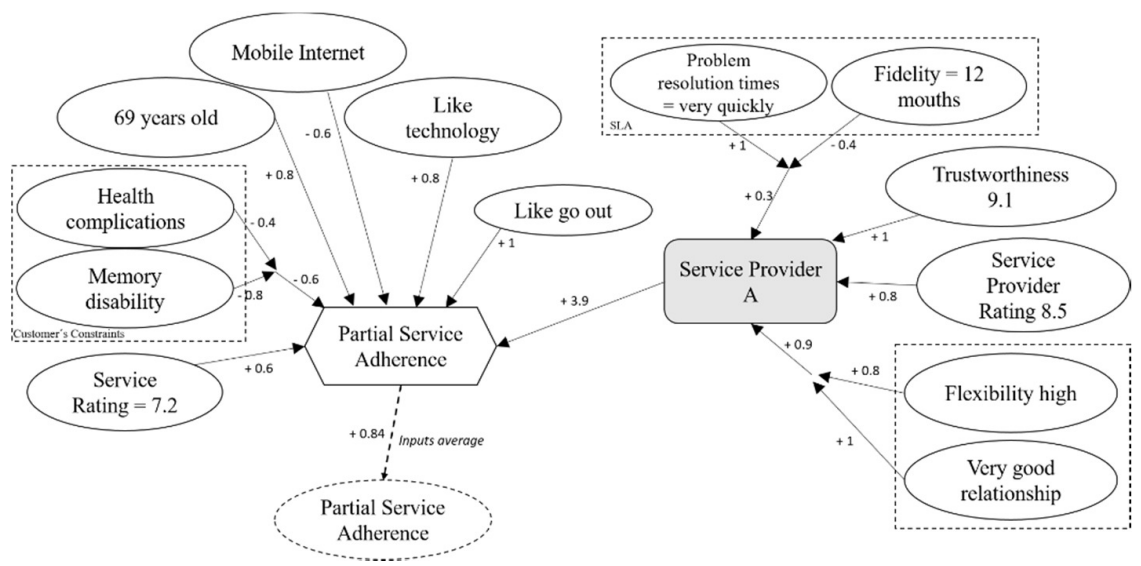

Fig. 9. Illustration of service s1 partial adherence calculation

Regarding service provider A, nodes and their influences are identified based on the CBE management strategies. Like service provider $\mathrm{A}$ is aggregation node, its 
influence corresponds the chance nodes sum. In the example, service s1 has one service provider. If $\mathrm{s} 1$ had two, both would participate in the causal network and the average influence would be taken.

For s1, the partial service adherence found is 0.84 (84\%). For each service node, a partial service adherence node is added to the causal network, and this node will be used in the second layer.

Let's consider that by applying the fuzzy causal network to services s 2 and s 3 , the value is 0.79 and 0.86 , respectively, we can then start the second layer of the fuzzy causal network.

The Fig. 10 shows the service adherence for each single service and for the service composition possibilities. For each service coverage level a fuzzy scale (Fig. 2) was pre-established when the service was inserted in the CBE.

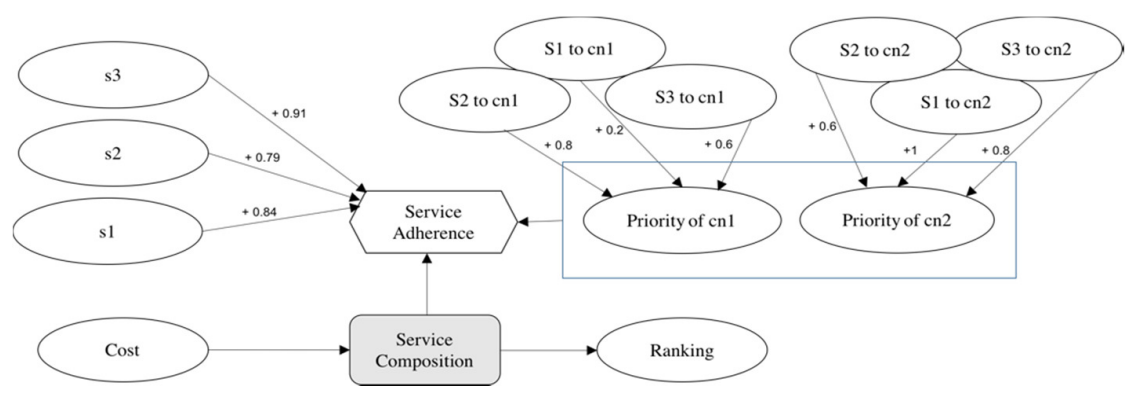

Fig. 10. Mary's service composition and ranking

The service adherence (SAD) is sum of the product between service coverage level and partial service adherence (PSA). For composite services, the service adherence is given by the maximum. As such, the following Table 2 could be generated.

Table 2 . Service Adherence for single and composite services

\begin{tabular}{ccccccc}
\hline & PSA & SCL $(\mathrm{cn} 1)$ & SAD $(\mathrm{cn} 1)$ & SCL $(\mathrm{cn} 2)$ & SAD $(\mathrm{cn} 2)$ & SAD \\
\hline \multicolumn{7}{c}{ Single services } \\
\hline S1 & 0,84 & 0,2 & 0,168 & 1 & 0,84 & 1,008 \\
\hline S2 & 0,79 & 0,8 & 0,632 & 0,6 & 0,474 & 1,106 \\
\hline S3 & 0,91 & 0,6 & 0,546 & 0,8 & 0,728 & 1,274 \\
\hline s1 and s2 & - & - & 0,632 & - & 0,84 & 1,472 \\
\hline s1 and s3 & - & - & 0,546 & - & 0,84 & 1,386 \\
\hline s2 and s3 & - & - & 0,632 & - & 0,728 & 1,360 \\
\hline s1, s2 and s3 & - & - & 0,632 & - & 0,84 & 1,472 \\
\hline
\end{tabular}


For Mary seven possibilities were found. Using service adherence, cost and number of providers as criteria, the best scorers are ranked (

Table 3).

Table 3. Rating of services for Mary

\begin{tabular}{ccccc}
\hline Rating & Services & Adherence & Cost & number of providers \\
\hline 1 & s1 and s2 & 1,472 & $44 €$ & 1 \\
\hline 2 & s1, s2 and s3 & 1,472 & $74 €$ & 2 \\
\hline 3 & s1 and s3 & 1,386 & $55 €$ & 2 \\
\hline 4 & s2 and s3 & 1,36 & $49 €$ & 2 \\
\hline 5 & S3 & 1,274 & $30 €$ & 1 \\
\hline 6 & S2 & 1,106 & $19 €$ & 1 \\
\hline 7 & S1 & 1,008 & $25 €$ & 1 \\
\hline
\end{tabular}

To illustrate the multi-criteria ranking, the cost and number of providers as constrains and criteria. In this case, Mary can access to four composite services, and tree single services. Integrated services S1 and S2 have the same adherence of services s1, s2 and s3 (see column "Adherence" in

Table 3). If only adherence is considered, they represent the first option for Mary, but the second also has higher cost. This cost can be negotiated by the coordinator of the CBE ecosystem, where multiple strategies can be applied, e.g. $10 \%$ discount when the service pack is provided by the same provider, or this represents an agreement between providers.

\section{Service S1 and service S2 have the same service provider (see row 1 in}

Table 3), so the subset of S1 and S2 is also delivered by one service provider. This can be an advantage, since an integrated service tends to be facilitated when provided by only one provider. On the other hand, it is risky, since a failure in the provision by this provider jeopardizes the provision of all services.

The service providers collaborative network for each customer is ultimately determined indirectly by services selection.

In our example scenario, care service providers for Mary depend on Mary's choice of services. If she chooses the first option, service provider is a single one. In contrast if she chooses the second option, a virtual organization $(V O)$ is created with two providers (Fig. 11). 


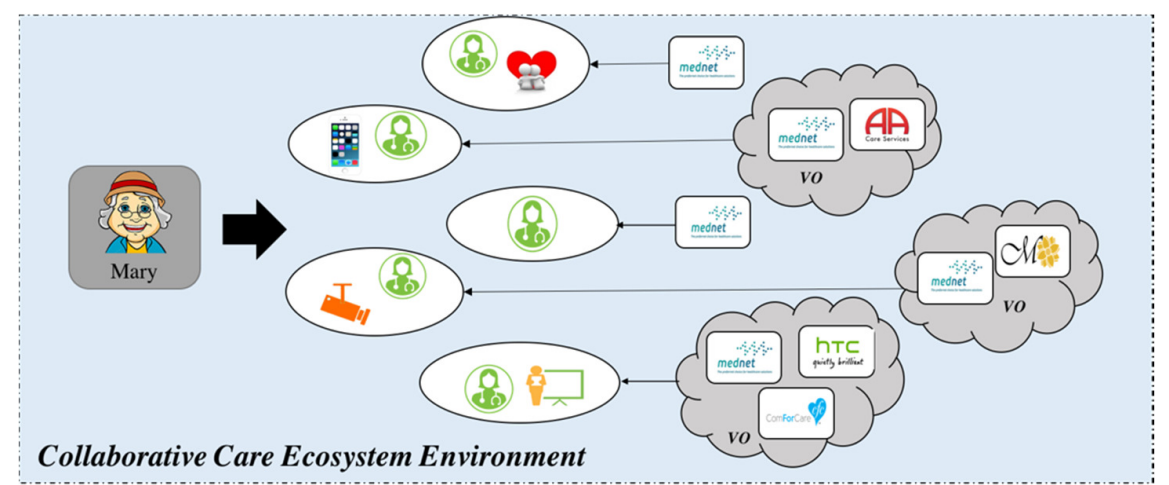

Fig. 11. Mary's potential care services providers

\section{Conclusions and Future Work}

Provision of personalized care services to elderly need to consider the life style aspects and the current customer's context [11]. If seniors and their family are satisfied with the provided services they will feel as unique individuals and are likely to remain loyal to the service provider [5]. Providers should seek this aspect, collecting feedback information in order to provide personalized services to their customers.

In this paper the service adherence criteria based on a fuzzy causal network for rating care services. Service adherence is part of the personalization process and represent the main criterion for finding the best personalized option to the customer.

The next phase of the work will be personalization mechanism refinement through setting multi-criteria parameters for matching between care needs and services and variable parameters like delivery time, integrated service historical data, ecosystem strategies, service loyalty time, incentives with some combined choices, etc. The last research step will address evolution mechanisms development for efficient service adaptation to evolving customer's life phase.

Acknowledgments. This work has been funded in part by the Center of Technology and Systems and the Portuguese FCT-PEST program UID/EEA/00066/2013, and by the Ciência Sem Fronteiras and Erasmus Mundi project (Brazil and European Commission).

\section{References}

1. HelpAgeInternational. (2014). Global AgeWatch Index 2014. Retrieved 10/03/2015, from http://www.helpage.org/global-agewatch/ 
2. Gartner, I. (2014). Applying Lessons From 20 Years of Hype Cycles to Your Own Innovation and Forecasting Strategies. Retrieved 10/03/2015, from http://www.gartner.com/doc/2847417?refval=\&pcp=mpe\#a-1321928256

3. Fengler, W. (2014, November, 2014). The End of the Population Pyramid. Retrieved May, 2015, from http://www.economist.com/blogs/graphicdetail/2014/11/daily-chart-10

4. Kearney, A. T. (2013). Understanding the Needs and Consequences of the Ageing Consumer. The Consumer Goods Forum. Retrieved 10/05/2015, 2015, from https://www.atkearney.com/documents/10192/682603/Understanding+the+Needs+and+Con sequences+of+the+Aging+Consumer.pdf/6c25ffa3-0999-4b5c-8ff1-afdca0744fdc

5. Lee, W.-P. (2007). Deploying personalized mobile services in an agent-based environment. Expert Systems with Applications, 32(4), 1194-1207.

6. Kwortnik Jr, R. J., Lynn, W. M., \& Ross Jr, W. T. (2009). Buyer monitoring: A means to insure personalized service. Journal of Marketing Research, 46(5), 573-583.

7. Evenson, S., \& Dubberly, H. (2010). Designing for service: Creating an experience advantage. In G. Salvendy \& W. Karwowski (Eds.), Introduction to service engineering (pp. 403-413). New Jersey - USA: John Wikey \& Sons.

8. LeadingAge. (2011). A Look into the Future: Evaluating Business Models for TechnologyEnabled Long-Term Services and Supports. Retrieved 11/04/2015, from http://www.leadingage.org/uploadedFiles/Content/About/CAST/CAST_Scenario_Planning. pdf

9. Hong, J., Suh, E.-H., Kim, J., \& Kim, S. (2009). Context-aware system for proactive personalized service based on context history. Expert Systems with Applications, 36(4), 7448-7457. doi: http://dx.doi.org/10.1016/j.eswa.2008.09.002

10. Manoharan, R., Ganesan, R., \& Sabarinathan, K. (2015). Impac of Hosted Speech Technology for Health Care Service Providers through Call Centers. Scholarly Research Journal for Interdisciplinary Studies, III, 2712-2724.

11. Baldissera, T. A., \& Camarinha-Matos, L. M. (2016). Towards a Collaborative Business Ecosystem for Elderly Care. In: M. L. Camarinha-Matos, A. J. Falcão, N. Vafaei \& S. Najdi (Eds.), Technological Innovation for Cyber-Physical Systems: 7th IFIP WG 5.5/SOCOLNET Advanced Doctoral Conference on Computing, Electrical and Industrial Systems, DoCEIS 2016, Costa de Caparica, Portugal, April 11-13, 2016, Proceedings (pp. 24-34). Cham: Springer International Publishing.

12. Camarinha-Matos, L. M., Afsarmanesh, H., Ferrada, F., Oliveira, A. I., \& Rosas, J. (2013). A comprehensive research roadmap for ICT and ageing. Studies in Informatics and Control, 22(3), 233-254.

13. Oliveira, A., \& Camarinha-Matos, L. (2014). Negotiation Support for Co-design of Business Services. In: L.M. Camarinha-Matos \& H. Afsarmanesh (Eds.), Collaborative Systems for Smart Networked Environments (Vol. 434, pp. 98-106): Springer Heidelberg.

14. Afsarmanesh, H., Sargolzaei, M., \& Shadi, M. (2012). A Framework for Automated Service Composition in Collaborative Networks. In L. Camarinha-Matos, L. Xu \& H. Afsarmanesh (Eds.), Collaborative Networks in the Internet of Services (Vol. 380, pp. 6373): Springer Berlin Heidelberg.

15. Camarinha-Matos, L. M., Ferrada, F., Oliveira, A. I., Rosas, J., \& Monteiro, J. N. (2013). Integrated Care Services in Ambient Assisted Living. IEEE 15Th Int. Conf. on e-Health Networking, Applications and Services (Healthcom 2013), Lisbon, 197-201.

16. Kosko, B. (1992). Neural networks and fuzzy systems: a dynamical systems approach to machine intelligence/book and disk. Vol. 1Prentice hall.

17. Howard, R. A., Matheson, J. E., \& Miller, K. L. (1977). Readings in decision analysis: Decision Analysis Group, Stanford Research Institute.

18. Eysenck, H. J. (2012). A model for personality: Springer Science \& Business Media. 